\title{
El concepto de la función administrativa y su delimitación frente a los actos de naturaleza jurisdiccional
}

\section{The Concept of The Administrative Function and its Delimitation Against Acts of a Jurisdictional Nature}

\author{
Alexander Espinoza Rausseo ${ }^{1}$ / Jhenny Rivas Alberti ${ }^{2}$
}

\section{RESUMEN}

Para distinguir entre una función administrativa y jurisdiccional tomaremos como punto de partida el criterio residual, así como su función de proteger los intereses generales. Por esa vía, aquellos casos que no puedan ser calificados de jurisdiccionales o legislativos serán de naturaleza administrativa.

Palabras clave: Función administrativa, acto jurisdiccional, intereses generales

\section{ABSTRACT}

To distinguish between an administrative and jurisdictional function, we will take as a starting point the residual criterion, as well as its function of protecting the general interests. In this way, those cases that cannot be classified as jurisdictional or legislative will be administrative in nature.

Keywords: Administrative function, jurisdictional act, general interests

\section{Introducción}

El contenido y significado de la función administrativa es un elemento determinante de la estructura del Estado. A partir de esa estructura básica, corresponde al legislador, en ejercicio de un amplio margen de

Doctor iuris Universität Passau, Alemania. Docente de la Universidad Autónoma de Chile, Chile. Correo electrónico: alexander.espinoza@uautonoma.cl.

2 Doctora en derecho, Universidad de Zaragoza, Espańa. Docente de la Universidad Autónoma de Chile, Chile..

Correo electrónico: jhenny.rivas@uautonoma.cl. 
evaluación, crear los órganos que estime necesarios para el cumplimiento de la Constitución Política de la República, mientras estos ciertamente no modifiquen el diseño que ella contiene (TC Rol No 1732$\left.10,2011,19^{\circ}\right)^{3}$. El concepto de función administrativa es, por motivos obvios, un elemento estructural de la definición y alcance del derecho administrativo, cuyo objeto es la regulación del ejercicio de la función administrativa dentro de las funciones del Estado, esto es, de la actividad administrativa (Brewer-Carías, 2015).

En Chile, el concepto de la función administrativa ha generado dificultades en el reconocimiento de la existencia de la potestad sancionatoria de la administración y su delimitación con respecto a la función jurisdiccional penal e incluso con respecto a la jurisdicción civil. A partir de la distinción entre funciones administrativas y jurisdiccionales se plantea un buen número de temas de especial complejidad. Algunos de ellos son los referidos a la controversia acerca de si es o no admisible el ejercicio de funciones jurisdiccionales por la administración del Estado, a la luz del principio de separación de funciones ${ }^{4}$, así como la interrogante de cuáles son los límites que debe respetar el legislador en la atribución al poder ejecutivo de funciones jurisdiccionales, tanto desde el punto de vista del principio de separación de poderes como de la garantía de un procedimiento racional y justo (TC Rol No 4012-17-CPR, 2018, 29 ${ }^{\circ}$ ). Pero, aun cuando no pretendemos desarrollar estos últimos temas, es claro que todo intento de resolver tales problemas jurídicos estará destinado a un resultado erróneo, si el concepto de la función administrativa y su delimitación frente a los actos de naturaleza jurisdiccional no ha sido desarrollado adecuadamente.

En numerosas ocasiones, el Tribunal Constitucional ha considerado necesario clasificar una atribución de los órganos del poder público, a partir de su naturaleza administrativa o jurisdiccional. Sin embargo, tal clasificación ha sido el resultado de la aplicación de criterios de diversa naturaleza, lo cual trae como resultado un panorama irregular y, no pocas veces, contradictorio. De tal forma, el Tribunal Constitucional ha calificado como actos jurisdiccionales la reclamación de filiación no matrimonial (TC No Rol 2690, 2015, $10^{\circ}$ ), la facultad del Servicio Nacional del Consumidor de resolver con imperio, entre otras materias; el cese de la conducta dañosa de intereses colectivos o difusos, el cálculo de indemnizaciones para los consumidores o la determinación de cautela del cumplimiento del acuerdo (TC Rol No 4012-17CPR, 2018, 33 $3^{\circ}$, así como constituirse en instancia de mediación y arbitrar una audiencia obligatoria de conciliación (TC Rol No 4012-17-CPR, 2018, 33 ) y, en general, la resolución de medios alternativos de solución de conflictos ${ }^{6}$.

Han sido clasificados por el Tribunal Constitucional como actos de naturaleza administrativa, la facultad de emitir informes que describen el grado de competencia y la estructura de un mercado relevante determinado del Tribunal de Defensa de la Libre Competencia (TC Rol No 1448-09, 2010, 20 y 21\%), así como la retención de impuestos por la Tesorería General de la República (TC Rol No 2865, 2015,

En cuanto al ámbito de evaluación del legislador en la configuración de la potestad sancionadora de la administración, véase TC Rol No 725-2007, 2008, 28 ; sobre la regulación de las actividades económicas: TC Rol No 480-06, 2006, 11\%; acerca de la libertad para definir los bienes jurídicos en materia penal: TC Rol No 2402-13, 2013, 23 y TC Rol № 2897-15, 2017, 45; sobre la determinación del órgano jurisdiccional que debe resolver las controversias entre la autoridad administrativa y los particulares afectados: TC Rol No 616-06, 2007, $30^{\circ}$; acerca de la decisión de sustituir o modificar el sistema de acciones y recursos respecto de las decisiones judiciales: TC Rol No 1448-09, $2010,42^{\circ}$.

Véase al respecto: Bordalí (2008).

5 Véase al respecto: Moraga (2011) 235, Cea (1982) 52I, Boettiger (2009, P. 580), Letelier (2017), van WeeZel (2017), ZúNiga (2007), Bordalí (2013), Bordalí (2009A), Gordillo (2017, IX-I3), LÜBbert (20 I I, P. 93).

${ }_{6}$ Es el caso de la mediación obligatoria en materia de salud (TC Rol № 2042-11, 2012, 30 ), de las comisiones conciliadora y arbitrales en concesiones de obras públicas (TC Rol No 236-96, 1996, 11\%), reiterado en TC Rol No 1536-09, 2009, 6º de los Tribunales Arbitrales en materias de Propiedad Industrial (TC Rol No 119-91,1991, 7o), de Registro de Variedades Protegidas (TC Rol No 195-94, 1994, 6º), de concesiones de bienes fiscales (TC Rol No 360-02, 2002, 7º) y de servicios de telecomunicaciones (TC Rolo 2191-12, 2012, 19º). 
$34^{\circ}$ y $35^{\circ}$ ). Por otra parte, ha sido calificada como una función jurisdiccional la facultad sancionatoria del Tribunal de Defensa de la Libre Competencia (TC Rol No 1448-09, 2010, 16º), así como la facultad del Servicio Nacional del Consumidor de imponer sanciones a los proveedores (TC Rol N ${ }^{\circ}$ 4012-17CPR, 2018, 33 $3^{\circ}$. Sin embargo, el Tribunal Constitucional ha considerado como actos administrativos las sanciones a cargo de los directores regionales del Servicio de Impuestos Internos (TC Rol No 725-2007, 2008, $12^{\circ}$ ), así como del Servicio Electoral (TC Rol N 3106-16-CPR, 2016, 15º).

A su vez, la resolución del ministro de Transportes y Telecomunicaciones, que otorga o deniega una concesión o un permiso de telecomunicaciones (TC Rol No 176, 1993, 3), ha sido considerada un acto jurisdiccional. La facultad de resolver acerca de la solicitud de derechos de aprovechamiento de aguas, aun cuando sea objeto de oposición por parte de terceros (TC Rol No 513-06, 2007, 12); así como el procedimiento de concursos públicos para el ingreso a la carrera funcionaria (TC Rol 4847-18, 2018, 7o; TC Rol 4945-18, 2018, 6º, son calificados como el ejercicio de una función administrativa.

Tampoco encontramos uniformidad en cuanto a los criterios utilizados por el Tribunal Constitucional para determinar la naturaleza administrativa o jurisdiccional de los actos de los órganos del poder público. En algunos casos ha sido determinante el criterio de la cosa juzgada (TC No Rol 2690, 2015, 10º), la solución de conflictos entre particulares por un tercero (TC Rol No 4012-17-CPR, 2018, 29º o simplemente el establecimiento o afectación de derechos de terceros (TC ROL No 176, 1993, 3º), la aplicación del derecho o la equidad mediante un raciocinio mental (TC Rol No 513-06, 2007, 12 ), la configuración legislativa de un procedimiento contencioso (TC Rol No 1448-09, 2010, 16º), así como la idoneidad de cumplir los requisitos de la garantía de un procedimiento racional y justo ${ }^{7}$.

Emplearemos el método del análisis conceptual, el cual sugiere una descomposición en partes simples de algo más complejo y un estudio de cómo estas partes se relacionan entre sí, a través de un proceso de abstracción que permita la formulación de una teoría general aplicable en los problemas complejos que se han planteado en la práctica judicial.

En el presente trabajo nos proponemos determinar cuáles son los criterios que permiten clasificar una función de naturaleza administrativa o jurisdiccional y, de ser necesario, cuáles correctivos se requieren para asegurar su correcta aplicación en la práctica. Delimitado de tal forma el objeto del trabajo, dejaremos de lado el análisis de las normas constitucionales de competencias del poder judicial, a la luz del principio de separación de funciones ${ }^{8}$, así como la interrogante de cuáles son los límites que debe respetar el legislador en la atribución al poder ejecutivo de funciones jurisdiccionales, tanto desde el punto de vista del principio de separación de poderes como de la garantía de un procedimiento racional y justo.

Para distinguir entre una función administrativa y jurisdiccional tomaremos como punto de partida el criterio residual, según el cual corresponden a la administración pública las materias distintas a las funciones legislativas y jurisdiccionales, así como su función de proteger los intereses generales. De tal forma, nuestros criterios de delimitación estarán referidos a los elementos que caracterizan la función jurisdiccional. Por esa vía, aquellos casos que no puedan ser calificados de jurisdiccionales o legislativos serán de naturaleza administrativa.

Véase al respecto, las referencias en nota $\mathrm{N}^{\circ} 4$.

8 Véase al respecto, Bordalí (2008). 


\section{Las funciones administrativas}

A pesar de los intentos de definición positiva, la determinación del ámbito de aplicación del derecho administrativo se remonta al método residual empleado a fines del siglo XIX por Otto Mayer: identificar los elementos característicos de la función legislativa y jurisdiccional; mientras que el resto de las funciones serían calificadas, por defecto, como una función administrativa (Mayer, 1895, p. 9). Este criterio se ha mantenido casi inalterado en el derecho administrativo alemán ${ }^{9}$ o, por lo menos, acompañado de una "determinación conceptual combinada" en el sentido de una orientación inicial del método residual o de sustracción, determinada por los elementos característicos de las restantes funciones del Estado y complementada con los elementos positivos del concepto de administración pública. Lo anterior, siguiendo la definición de Stern, en el sentido de la responsabilidad y autonomía (en interacción con los afectados) en la resolución de las funciones públicas de interés general, a través de medidas sujetas al derecho (Ehlers, 2010, p. 8).

En Chile ha precisado el Tribunal Constitucional que las funciones administrativas apuntan satisfacer necesidades públicas de manera regular y continua (TC Rol No 2865, 2015, 35º Rol No 3594-17, 2018, $33^{\circ}$ ). Sin embargo, se trata de una definición tan amplia que obliga a emplear el método de delimitación negativa (Silva, 2009, p. 26) ${ }^{10}$. En todo caso, como un elemento material que caracteriza la función administrativa, encontramos la defensa de los intereses generales (Moraga, 2011, p. 235; Colombo, 1991, p. 45), como la contrapartida de la resolución de conflictos entre intereses individuales, que define la función jurisdiccional civil ${ }^{11}$.

\section{Las características de la función jurisdiccional civil}

La función jurisdiccional podría ser definida desde el punto de vista orgánico como "la ejercida con carácter exclusivo por los jueces y tribunales, aplicando las normas jurídicas en los juicios civiles, penales y contencioso-administrativos, juzgando de modo inmutable y ejecutando lo juzgado" (Penalva, 1976, p. 161). Sin embargo, debemos procurar determinar los elementos que configuran el ejercicio de la función jurisdiccional desde un punto de vista material, por cualquier órgano ${ }^{12}$, partiendo de la idea general que, en teoría, podrían serle atribuidas al órgano administrativo no solo funciones administrativas, sino también legislativas y jurisdiccionales (Gordillo, 2017, pp. IX-9; Brewer-Carías, 1983, p. 694; 2015, p. 15; González, 2014, p. 121).

Según la doctrina del Tribunal Constitucional, la jurisdicción consiste en el poder-deber que tienen los tribunales para conocer y resolver, por medio del proceso y con efecto de cosa juzgada, los conflictos de intereses de relevancia jurídica que se promuevan, en el orden temporal, dentro del territorio de la república y en cuya solución les corresponda intervenir (TC Rol 165-93, 1993, 1 TC Rol o 2865,

9 Véase BVerwG (2011), Wienbracke (2012), Brühl (2006), Bull y Mehde (2014), y Von Münch (2016), quien propone distinguir además entre las funciones de la administración y el gobierno.

10 Este método ha sido empleado por el Tribunal Constitucional al analizar la naturaleza jurídica de los actos de retención de la Tesorería, en TC Rol No 2865, 2015, 35 ; y TC Rol No 3594-17, 2018, $33^{\circ}$.

11 En el caso del ejercicio de la potestad informativa del Tribunal de Defensa de la Libre Competencia, el Tribunal Constitucional observó que, en cuanto al fundamento y objetivo, esta dice relación con la protección del bien jurídico de la libre competencia en los mercados monopólicos y no dirime propiamente un conflicto de relevancia jurídica, por lo que debía ser calificado como una competencia de carácter administrativo (TC Rol No 1448-09, 2010).

12 Este criterio ha sido sostenido en varias ocasiones por el Tribunal Constitucional (TC Rol No 478-06, 2006, 13; TC Rol No 1393-09, $2010,7^{\circ}$ ) y por Colombo (1991), según el cual las autoridades administrativas a las cuales la ley le ha otorgado especialmente el ejercicio de facultades jurisdiccionales son tribunales de justicia. 
2015, 35; TC Rol No 3594-17, 2018, 33; TC Rol No 346, 2002, 43; TC Rol No 606-2006, 2006, 9o; Colombo, 1991, p. 41; 2001, p. 15; Lübbert, 2011, p. 90; Moraga, 2011, p. 235; Cea, 2008, p. 29).

De acuerdo con lo expuesto, podemos centrar nuestro análisis en torno a tres elementos que han sido señalados como característicos de la función jurisdiccional: la resolución de conflictos entre particulares, el efecto de cosa juzgada de la decisión ${ }^{13}$ y la imparcialidad del órgano. Estos elementos se encuentran implícitos en el texto del artículo 76 de la Constitución Política de la República, el cual alude a "la facultad de conocer de las causas civiles y criminales, de resolverlas y de hacer ejecutar lo juzgado".

Desestimaremos, sin embargo, los elementos relacionados con el efecto de cosa juzgada ${ }^{14}$ y la imparcialidad del órgano, en cuanto a su idoneidad para servir de criterio determinante de la existencia de una función jurisdiccional. En ambos casos se trata solo de una consecuencia y no presupuesto de la existencia de una controversia civil, cuyo desarrollo excedería los límites del presente estudio.

\subsection{La potestad de aplicar las leyes}

La Constitución de 1822, inspirada en la Constitución Norteamericana de 1787 y en la Constitución de Cádiz de 1812 (Zúñiga, 1998, p. 222), definía la función del Poder Judicial como "la potestad de aplicar las leyes". La expresión se encontraba contenida en el artículo 242 de la Constitución de Cádiz, pasando por casi todos los textos constitucionales españoles del siglo XIX, hasta el artículo 91 de la Constitución de 1869 (Ramos, 1984, p. 420). La potestad de aplicar las leyes es entendida en el sentido de aplicación del derecho objetivo en los casos concretos. Si bien la aplicación del derecho también se produce a través de la actividad administrativa, al respecto se ha precisado que la potestad jurisdiccional no es un mero comportamiento con arreglo a las normas jurídicas, sino la realización en concreto de las reacciones previstas por el ordenamiento para el caso de que el comportamiento no se ajuste a la norma o exista un peligro de infracción de esta (Ramos, 1984, p. 422; Cea, 1979, p. 300) 15 .

El criterio expuesto no nos permite resolver la diferencia entre una sanción administrativa o penal, ni entre la resolución de conflictos entre intereses individuales por la administración o por los jueces civiles, pero podría, sin embargo, resultar muy productivo para la distinción entre la función administrativa y la jurisdicción contencioso-administrativa.

13 Véase, con respecto a la cosa juzgada como característica del acto jurisdiccional: TC No Rol 2690, 2015, $10^{\circ}$.

14 Un argumento de tal naturaleza reconduciría siempre hacia el criterio orgánico, en razón de que, en contra de los actos de la administración que afecten derechos individuales es procedente el control judicial, en virtud de lo dispuesto en el artículo 38, inciso segundo, de la Constitución. Por tal motivo, no seguiremos el método utilizado por el Tribunal Constitucional, al pronunciarse acerca de la naturaleza jurídica de los actos de retención de la Tesorería, en TC Rol No 2865, 2015, 35º; Rol № 3594-17, 2018, 33º. También, en ese sentido, el voto en contra de los ministros seńores Carlos Carmona Santander, Gonzalo García Pino y Nelson Pozo, en TC Rol No 4012-17-CPR, 2018. Tampoco compartimos el criterio del Tribunal Constitucional, que estimó reforzado el carácter jurisdiccional de la sanción impuesta por el SERNAC, en virtud de que, de acuerdo con lo dispuesto en el artículo $50 \mathrm{~S}$ del proyecto, en un juicio posterior, donde se demande alguna indemnización no podrá discutirse la infracción que ha sido sancionada por el Servicio Nacional del Consumidor mediante resolución firme, en TC Rol No 4012-17-CPR, 2018, 35.

15 Desde este punto de vista, el concepto de función jurisdiccional se encontraría asociado con una relación de concordancia (no contradicción) entre normas o conjuntos normativos de diverso grado jerárquico (TC Rol No 3028-16, 2016, 3º; TC 2921-15, 2016, 30; Ferrajoli (2005), GonzÁlez (20I4), Lübbert (20I I), Cea (i 1979). En cuanto al sistema de valores de la Constitución, véase TC Rol No 740, 2008 ,

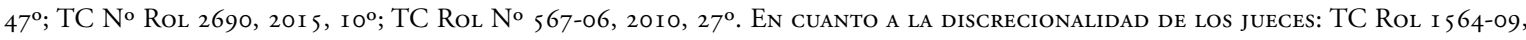
$2010,33^{\circ}$. 


\subsection{La protección de intereses individuales}

Desde el punto de vista de la distinción entre el derecho subjetivo y los mecanismos de protección, la jurisdicción es concebida como garantía de la efectividad del derecho de acción (González, 2014, p. 126). La función jurisdiccional tiene por objeto la constatación y sanción o reparación de la lesión de un derecho subjetivo (Ferrajoli et al, 2001, p. 26; González, 2014, p. 130; Alcalá-Zamora y Castillo, 1992, p. 51; Bordalí, 2007, p. 7 y 2013; RAMOS, 1984, P. 424 ${ }^{16}$. El Tribunal Constitucional ha hecho suya la definición de Couture en el sentido que la función jurisdiccional es "la función pública, realizada por órganos competentes del Estado, con las formas requeridas en la ley, en virtud de la cual, por acto de juicio, se determina el derecho de las partes, con el objeto de dirimir sus conflictos y controversias de relevancia jurídica, mediante decisiones con autoridad de cosa juzgada, eventualmente factibles de ejecución" (TC Rol No 1448-09, 2010,13ㅇ). Desde el punto de vista material u objetivo, la función jurisdiccional puede ser definida como la "decisión con fuerza de verdad legal de una controversia entre partes" (Gordillo, 2017, IX-12). La diferencia específica del juicio respecto de la administración reside en una relación de dos partes y un juzgado, una relación asociada con la resolución de un tema de competición (Damaška, 2000, p. 155; Fuenzalida y Valderrama, 2017, p. 189).

\subsection{La determinación de derechos subjetivos}

De acuerdo con lo anterior, el ámbito de acción de la función jurisdiccional no está puesto en los intereses generales, sino en los derechos subjetivos, intereses legítimos y posiciones jurídicas que manifiestan los litigantes en el proceso (Moraga, 2011, pp. 235, 237), mientras que el ámbito natural donde actúa la administración es el de los intereses generales (p. 235). La aplicación práctica de este criterio de delimitación encontrará los problemas que son propios de la aplicación de la teoría de los derechos subjetivos (Pacheco, 1990, p. 136; Valdés, 1953, p. 227), cuyo estado actual ha permanecido, con ciertas modificaciones, en el sentido de la combinación de las teorías de la voluntad y del interés (Scherzberg, 1988, p. 129; Coing, 1959a, Coing, 1959b, p. 14; Rupp, 1965, p. 155; Bauer, 1986, p. 75; Schapp, 1977, p. 70; Fezer, 1985, p. 770). Conceptualmente, el derecho subjetivo es un poder jurídico, que le ha sido otorgado al individuo por el ordenamiento jurídico, pero según su finalidad es un medio de satisfacción de intereses humanos (Schapp, 1977, p. 86).

\subsection{Exclusión de conflictos de derechos subjetivos públicos}

La noción de "conflictos de intereses de relevancia jurídica" ha sido definida como la actividad capaz de establecer o afectar derechos de terceros. A través de este criterio, el Tribunal Constitucional ha declarado que la resolución del ministro de Transportes y Telecomunicaciones, que otorga o deniega una concesión o un permiso de telecomunicaciones, constituye el ejercicio de funciones jurisdiccionales (TC Rol No 176, 1993, 3ㅇ. Según el tribunal, en el concepto "causas civiles" a que se refiere el artículo 73 de la Constitución, se deben incluir todas aquellas controversias jurídico-administrativas que afectan los derechos de las personas (TC Rol No 176, 1993, 60) ${ }^{17}$

Sin embargo, estimamos que se trata de una definición demasiado amplia. Por ello, debemos incorporar a la noción de "conflictos de intereses de relevancia jurídica" en controversias civiles, un elemento adicional que permitirá distinguirlo adecuadamente de la función administrativa. La función jurisdiccional civil consiste entonces en la resolución de conflictos de intereses de relevancia jurídica, de derechos subjetivos

16 Véase también una relación detallada de las teorías subjetivas y objetivas de la función jurisdiccional en Pérez-Cruz (2015) y Nieva (2017).

17 Desde el punto de vista del principio de imparcialidad, véase Bordalí (2009 b, p. 292). 
entre particulares y no de derechos subjetivos frente al Estado18. Se trata de la función de resolver la confrontación de pretensiones y resistencias o un conflicto intersubjetivo de intereses (Bordalí, 2009a y 2013) entre particulares, a diferencia de la función administrativa, orientada a una valoración de los intereses generales (Ferrajoli, 2005, p. 88; González, 2014, p. 130).

Para el desarrollo de una fórmula que permita identificar la existencia de un derecho subjetivo público, acudiremos a la teoría que ha sido desarrollada en el derecho alemán desde inicios del siglo XX por Georg Jellinek y Othmar Bühler, a partir del concepto de derechos subjetivos en la teoría general del derecho, basada en el derecho privado (Bauer, 1986, p. 73; Scherzberg, 1988, p. 129; Rupp, 1965, p. 155; Krebs, 1985, p. 195; Bachof, 1968, p. 10; Bachof, 1955, p. 295; Bühler, 1955, p. 270; Lüke, 1959, p. 185; Preu, 1992, p. 123; Ramsauer, 1981, p. 504; Redeker, 1983, p. 863). Debemos considerar además que, en su estado actual, la teoría de los derechos subjetivos públicos se encuentra determinada por la influencia de los derechos fundamentales (Roth Andreas, 1994, p. 37; Bauer, 1988, fn. 11; Schmidt-Preuß, 1992, p. 41; Schmidt-Aßmann, 1991, rdnr. 21).

La tarea de interpretación de cuándo una norma está destinada proteger los intereses del individuo se complica, porque los intereses individuales no siempre se oponen a los intereses generales, ni los excluyen (Wolff et al, 2007, p. 573; Bachof, 1968, p. 64; Neumeyer, 1979, p. 34; Bauer, 1988, p. 595; Ramsauer, 1986, p. 509).

La finalidad protectora de una norma puede ser determinada de acuerdo a la interpretación literal de la misma, según su sentido y finalidad, así como a partir de su significado en el ámbito de la ley que la contiene (Schmidt-Aßmann, 1998, pp. 2-60; Wolff et al, 2007, p. 565; Neumeyer, 1979, p. 34). Los derechos fundamentales pueden jugar un papel de soporte interpretativo (Schmidt-Aßmann, 1998, pp. 2-60). En la práctica, la jurisprudencia alemana toma diversos criterios en consideración (la afectación real, la necesidad de protección jurídica, la determinabilidad del ámbito de los afectados), los cuales no necesariamente guardan relación con el contexto de la norma o la intención del legislador (Pietzcker, 1997, p. 288; Wolff et al, 2007, p. 565; BVerwG, 1982; BVerwG, octubre 1986).

En el derecho público, a diferencia del derecho privado, no siempre corresponde un derecho subjetivo a cada obligación de un órgano del Poder Público. Se deben diferenciar entonces los verdaderos derechos de simple "efectos reflejos" del derecho objetivo (Wolff et al, 2007, p. 565; Sodan, 2010, rdnr. 379; Schmidt-Preuß, 1992, pp. 92-225; Ramsauer, 1986, p. 509; BVerwG, septiembre 1986; BVerwG, 1993; BVerwGE, 1987; Gröschner (1997) p. 306; BVerwGE, abril 1967; BVerwG, 1977; Roth Andreas, 1994 , p. 38.

La característica que distingue al interés simple del verdadero derecho subjetivo o interés jurídicamente protegido es la afectación inmediata y directa de un bien jurídico del sujeto titular. Solo el interés directo puede ser considerado un derecho subjetivo, si además se encuentra protegido por una norma. De lo contrario, el interés indirecto puede ser un mero interés fáctico o un interés general. La densidad de la relación entre la actuación que genera la afectación y el efecto lesivo debe ser establecida, en primer lugar, a partir de la longitud de la cadena causal entre el acto del Poder Público y el efecto sobre el afectado (Ramsauer, 1981, p. 103; Roth Wolfgang, 1994, p. 33; Heintzen, 1990, p. 544).

18 Con respecto a la función jurisdiccional en el contencioso-administrativo, ver TC Rol No 616-06, 2007, $25^{\circ}$. 


\subsection{Los procedimientos contenciosos}

La consecuencia en el procedimiento de la existencia de un conflicto entre partes se refleja en la configuración legislativa de un procedimiento contencioso. Este elemento fue tomado en consideración por el Tribunal Constitucional, en la calificación de las competencias administrativas atribuidas al Tribunal de Defensa de la Libre Competencia (TC Rol No 1448-09, 2010, 16º).

\subsection{La resolución imperativa de controversias}

Debemos hacer también referencia a la resolución de controversias, como uno de los elementos que derivan de la finalidad de la jurisdicción, a partir del concepto de derecho subjetivo. La crítica de esta teoría ha advertido que la resolución de la controversia puede ser encomendada a órganos no jurisdiccionales, sino de arbitraje o conciliación (Pérez-Cruz, 2015, p. 14). Pero, como hemos señalado anteriormente, no es el órgano el elemento idóneo para definir la naturaleza material de la función jurisdiccional ${ }^{19}$.

A efectos de nuestro estudio resulta interesante analizar si las vías alternativas de resolución de conflictos comparten la misma naturaleza del acto jurisdiccional. Mientras que el Tribunal Constitucional ha resuelto invariablemente el problema en forma afirmativa ${ }^{20}$, en la doctrina es un tema muy controvertido. La diversidad de criterios resulta además compleja debido a la pluralidad de vías alternativas de resolución de conflictos y a sus características particulares ${ }^{21 .}$

Las diversas posturas se refieren especialmente al elemento de voluntariedad que es propio de tales instituciones. Este criterio se plantea con mayor intensidad en las formas negociadas de solución de conflictos, tales como la negociación y la mediación y, en menor medida, en el arbitraje. Según tal criterio, el elemento de la voluntariedad constituye un importante elemento diferenciador frente al juicio civil, en el cual produce una decisión imperativa de contiendas entre partes. Sin embargo, estimamos que tales objeciones olvidan que el elemento de voluntad es inherente al concepto del derecho subjetivo, por lo que la disponibilidad de los bienes jurídicos en juego se refleja en no pocas oportunidades en el proceso civil. En sentido inverso, también encontramos una variable intensidad del ejercicio del poder de imperio del juez. El elemento que sí permanece invariable es la participación de un tercero, en la solución de un conflicto intersubjetivo. En la medida en que tal elemento también caracteriza a los mecanismos alternativos, entonces tendríamos que admitir que estos también constituyen el ejercicio de una función jurisdiccional.

\subsection{La delimitación entre sanciones penales y administrativas}

En el derecho comparado, el Tribunal Federal Constitucional de Alemania ha precisado que la competencia de los órganos de la administración pública, para imponer sanciones pecuniarias, no constituye una materia penal, sino simple derecho administrativo (BVerfGE, 1958). También ha precisado que la norma penal contiene un juicio de desvalor ético-social, mientras que las contravenciones se refieren a ciertas

\footnotetext{
Ejemplos de mediación por órganos administrativos los encontramos en el ejercicio de la Inspección del Trabajo de mecanismos de conciliación obligatoria, con el objeto de resolver el eventual conflicto individual, así como la función de mediación laboral encargada a la Inspección del Trabajo, en materia de conflictos colectivos. Al respecto, véase Ugarte (2008, p. 193).

21 Véase al respecto: Chocrón (2005, p. 667), Barona (2011, pp. 199, 207). En criterio de Moraga (2011, p. 247), en los casos en que la autoridad administrativa que hace de árbitro arbitrador actúa en función jurisdiccional. Véase también Pérez y Copani (2010, p. 159). Igualmente, en el derecho comparado, véase el artículo 116 de la Constitución de Colombia, el cual alude a "la función de administrar justicia" (CCC, C-330/12; C-961/06); Gómez (2010, p. 382), Gordillo (2017, IX-5) y Brewer-Carías (2015, p. 17). También alude a la disponibilidad del derecho Bordalí (2004) o al efecto de cosa juzgada, Jequier (2018).
}

$20 \quad$ Nota 8. 
situaciones de menor gravedad (BVerfGE, 1969; BVerfGE, junio 1967; Lagodny, 1996). Un criterio similar ha sido sostenido por el Tribunal Constitucional de Chile. La posibilidad de que una determinada conducta sea sancionada por la vía administrativa o judicial es considerada una cuestión de política legislativa (TC Rol No 725-2007, 2008, 28; TC Rol No 3106-16-CPR, 2016, 15; TC Rol No 480-06, 2006, 11\%; Cordero (2013 a, p. 96; 2013 b, p. 128). En todo caso, podemos precisar que la separación entre sanciones penales y administrativas pasa por problemas relacionados con la naturaleza de los bienes jurídicos protegidos (Bordalí, 2018, p. 518), la gravedad de la lesión y el tipo de sanciones, especialmente en cuanto a las penas privativas de libertad ${ }^{22}$.

En principio, la facultad de un órgano administrativo de aplicar, rebajar o condonar sanciones administrativas, se enmarca dentro de sus potestades administrativas sancionatorias, que no suponen ejercicio de jurisdicción (TC Rol No 725-2007, 2008, 12²) ${ }^{23}$. Con ello, podemos considerar superado el criterio que afirmaba que la función de sancionar supone juzgar, lo cual pertenecería con exclusividad a los jueces (Soto, 1979, p. 95; 2013, pp. 495 y sig.; Aróstica, 1987, p. 72; Cea, 2008, p. 30). Mientras que las multas constituyen las sanciones típicas del derecho administrativo, lo propio cabe aseverar de las penas privativas de libertad respecto del ámbito penal (TC Rol No 1518-09, 2009, 5; TC Rol No 2381-12, 2013, 16\%; TC Rol No 1448-09, 2010, 10º; Rodríguez, 2010).

En el caso de las facultades sancionatorias del Tribunal de Defensa de la Libre Competencia nos encontramos con una situación de especial complejidad (TC Rol No 2381-12, 2013, 16º; TC Rol No 1448-09, 2010, 10; Rodríguez, 2010). Recordemos que, por razones históricas y presupuestarias, hoy se encuentra radicada en el Tribunal de Defensa de la Libre Competencia la facultad sancionatoria, además de otras potestades que no son propiamente jurisdiccionales (TC Rol No 1448-09, 2010, 16º).

\section{Las relaciones jurídicas multipolares}

El concepto de relación jurídica está referido a la relación entre, por lo menos, dos sujetos de derecho, en base a la cual uno de ellos debe o puede hacer o no hacer algo frente al otro (Jellinek, 1929, p. 180). La teoría de las relaciones jurídicas triangulares o multipolares tiene su origen en el derecho administrativo alemán, para resolver una colisión entre intereses privados por parte de una autoridad administrativa (Preu, 1992, p. 33; Schmidt-Preuß, 1992, p. 433; Wolff et al, 2007, p. 566). Su aplicación en derecho constitucional nos permitirá construir una teoría integrada de las relaciones jurídicas, la cual comprende, por una parte, el bien jurídico protegido, que pone en marcha la actuación del Estado; y por otra, el derecho de libertad afectado, en el caso de actuaciones de intervención del poder público.

Desde ese punto de vista podemos formular las siguientes hipótesis:

- Una función legislativa se caracteriza por una regulación general y abstracta, mientras que las funciones administrativas y jurisdiccionales tienen un carácter particular y concreto, que se ponen en movimiento a partir de la obligación del Estado de proteger bienes jurídicos. La configuración legislativa de la

22 Véase además: TC Rol 244-96, 1996, 9; Cordero y Aldunate (2012, p. 347), Cordero (2013 b, p. 129; 2014, p. 401), van Weezel (2017), Couso (2018). Véase también, con abundantes referencias a la jurisprudencia espańola, Cabrera (2014). En sentido contrario, véase Blanco (2004, p. 139) y Letelier (2017, p. 636), quienes niegan la diferencia ontológica entre ambas sanciones.

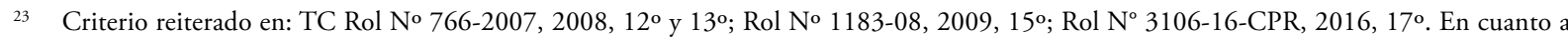
sanciones aplicadas por la autoridad sanitaria, véase TC Rol No 792-07, 2008, 16; y Román (2010, p. 158). Con más referencias sobre la evolución jurisprudencial: Boettiger (2009, p. 580). 
forma de protección de tales bienes jurídicos es determinante de la distinción entre una actuación del Estado de naturaleza jurisdiccional (civil, penal o administrativa) o una función administrativa.

- Una función jurisdiccional civil se plantea en la resolución de conflictos, en que el Estado se encuentra obligado a brindar protección a bienes jurídicos y el legislador ha resuelto limitar la libertad de un individuo. La forma de protección de tales bienes jurídicos es la protección directa e inmediata de un interés individual, otorgando a un particular un poder jurídico para exigir una conducta de otro particular (por ejemplo: cumplimiento de contrato o indemnización de daños). Deben excluirse de este concepto los casos de derechos subjetivos frente al Estado.

- De acuerdo con la teoría de la norma protectora, debe determinarse en cada caso si la norma también se encuentra destinada a proteger intereses individuales y no solo intereses generales. Para resolver las dificultades prácticas de la teoría de la norma protectora, formularemos las siguientes hipótesis:

o La imposibilidad material de separar de forma absoluta la protección individual de la protección del interés general es la contrapartida de la imposibilidad de separar por completo la función jurisdiccional de la función administrativa. Solo podemos distinguir entre una función de protección primaria de intereses individuales, a través de un acto jurisdiccional, frente a una protección primaria del interés general, a través de un acto administrativo. Esta jerarquización permitiría, por ejemplo, resolver, en sentido negativo, la difícil interrogante de si la función fiscalizadora de Dirección del Trabajo tiene o no una naturaleza jurisdiccional. No puede rechazarse de plano que, al momento de fiscalizar, tal órgano resuelve conflictos entre las partes del contrato de trabajo, pero se trata de la protección primaria del interés general, a través de un acto administrativo (Ugarte, 2008, p. 201) $)^{24 .}$

o En casos en que la norma procura la satisfacción de las pretensiones del individuo, resulta claro que tiene una finalidad primaria de protección de derechos subjetivos, que prevalece frente a la función de defensa del orden jurídico objetivo. Tal sería el caso del procedimiento de mediación a cargo del SERNAC.

o Para determinar si la potestad sancionatoria ha sido concebida con la finalidad primaria de proteger los derechos subjetivos del afectado por la conducta ilícita, debemos distinguir entre los elementos de la norma destinados a la regulación de la conducta y la disposición que establece la pena (Lagodny, 1996, p. 55). La prohibición implícita en la norma sancionatoria puede servir de fundamento a una pretensión de derecho subjetivo, como en el caso de la indemnización de daños. Pero la sanción es establecida generalmente con una finalidad preventiva, por lo que prevalece el elemento de protección del interés general 25.

- Una función jurisdiccional penal se plantea en la resolución de conflictos, en que el Estado se encuentra obligado a brindar protección a bienes jurídicos y el legislador ha resuelto limitar la libertad de un individuo. La forma de protección de tales bienes jurídicos es la protección mediata o refleja del individuo, a través de la protección de un interés general, que consiste en un reproche ético por la

Para Ugarte (2008) no se trata de una actuación jurisdiccional, porque su resolución no es definitiva y es modificable, precisamente, por los tribunales de justicia.

25 En el voto autónomo del ministro señor Juan José Romero Guzmán, se alude a la función disuasoria de la imposición de multas, en TC Rol $\mathrm{N}^{\circ}$ 4012-17-CPR, 2018, 15․ Sobre la teoría de la disuasión, véase Bensusán (2009, p. 994). Ver también Cordero (2013 b, p. 126), TC Rol N ${ }^{\circ}$ 4012-17-CPR, 2018, 41; voto en contra de los ministros señores Carlos Carmona Santander, Gonzalo García Pino y Nelson Pozo, en TC Rol No 4012-17-CPR, 2018. 
realización de una conducta socialmente dañina, utilizando generalmente penas privativas de libertad. En estos casos, a diferencia de la sanción, la prohibición de la conducta puede servir de fundamento a pretensiones de derecho subjetivo, que deben ser resueltas a través de una función jurisdiccional civil.

- Una función administrativa se plantea en la resolución de conflictos, en que el Estado se encuentra obligado a brindar protección a bienes jurídicos y el legislador ha resuelto limitar la libertad de un individuo. La forma de protección de tales bienes jurídicos es la protección mediata o refleja del individuo, a través de la protección de un interés general (por ejemplo: requisitos sanitarios).

- Una función administrativa se plantea en la resolución de conflictos, en que el Estado se encuentra obligado a brindar protección a bienes jurídicos y el legislador ha resuelto establecer un mecanismo de protección directa e inmediata de un interés individual, otorgando a un particular un poder jurídico para exigir una conducta positiva del Estado, sin limitar la libertad de otro individuo. Encontraremos en este caso el concepto de derecho subjetivo público, de carácter prestacional (por ejemplo: prestaciones directas de derecho social o deberes de protección).

- Una función administrativa se plantea en la resolución de conflictos, en que el Estado se encuentra obligado a brindar protección a bienes jurídicos y el legislador ha resuelto limitar la libertad de un individuo. La forma de protección de tales bienes jurídicos es la protección mediata o refleja del individuo, a través de la protección de un interés general, que consiste en un reproche menos grave, utilizando solo penas distintas a la privación de libertad, generalmente de multa. En estos casos, a diferencia de la sanción, la prohibición de la conducta puede servir de fundamento a pretensiones de derecho subjetivo, que deben ser resueltas a través de una función jurisdiccional civil (por ejemplo: la Inspección del Trabajo).

- Una función jurisdiccional contencioso-administrativa se plantea en términos materiales idénticos a la función administrativa, salvo por elementos orgánicos y de procedimiento. En este caso, podría ser de utilidad el criterio que distingue entre la aplicación de la ley, con arreglo a las normas jurídicas, por una parte, y, por la otra, la realización en concreto de las reacciones previstas por el ordenamiento para el caso de que el comportamiento no se ajuste a la norma o exista un peligro de infracción de esta.

\section{Conclusiones}

De acuerdo con el criterio residual, el contenido de la función administrativa puede ser determinado a partir de la identificación de los elementos característicos de las funciones legislativa y jurisdiccionales. El resto de las funciones pueden ser calificadas, por defecto, como funciones administrativas. El método residual o de sustracción puede ser complementado con los elementos positivos del concepto de administración pública, tales como el principio de responsabilidad en la protección del interés general.

La función jurisdiccional solo es accesible a través de los elementos que son propios de la jurisdicción civil, penal y contencioso-administrativa, cuya diversidad impide reducirlos en un concepto general de función jurisdiccional. El elemento distintivo de la función jurisdiccional civil lo constituye la participación de un tercero, en la solución de un conflicto intersubjetivo. 


\section{Bibliografía citada:}

Alcalá-Zamora y Castillo, Niceto (1992): Estudios de teoría general e historia del proceso (1945-1972) (México D.F., Universidad Nacional Autónoma de México), Tomo I.

Aróstica, Iván (1987): “Algunos problemas del Derecho Administrativo Penal”, Revista de Derecho Universidad de Concepción, 182: pp. 71-81.

Bachof, Otto (1955): "Reflexwirkungen und subjektive Rechte im öffentlichen Recht”, en Bachof, Otto; Draht, Martin; Gönnenwein, Otto y Walz, Ernst (autores), Forschungen und Berichte aus dem öffentlichen Recht. Gedächtnisschrift für Walter Jellinek (München Isar Verlag).

Bachof, Otto (1968): Die verwaltungsgerichtliche Klage auf Vornahme einer Amtshandlung (Tübingen, Mohr Siebeck).

Bauer, von Hartmut (1986): Geschichtliche Grundlagen der Lehre vom subjektiven öffentlichen Recht (Berlin: Duncker und Humblot).

Bauer, von Hartmut (1988): "Altes und neues zur Schutznormtheorie", Archiv des öffentlichen Rechts, 113, 4: pp. 582-631.

Bordalí Salamanca, Andrés (2007): “Análisis crítico de la función e independencia judicial en el Derecho chileno", en Couso, Jaime y Atria, Fernando (editores), La judicatura como organización (Santiago: Instituto de Estudios Judiciales).

Bordalí Salamanca, Andrés (2008): "La doctrina de la separación de poderes y el poder judicial chileno", Revista de derecho, 30: pp. 185-219.

Bordalí Salamanca, Andrés (2009 a): "Organización judicial en el derecho chileno: un poder fragmentado", Revista chilena de derecho, 36, 2: pp. 215-244.

Bordalí Salamanca, Andrés (2009 b): "El derecho fundamental a un tribunal independiente e imparcial en el ordenamiento jurídico chileno", Revista de derecho, 33: pp. 263-302.

Bordalí Salamanca, Andrés (2013): "La independencia de los jueces en la aplicación de la ley dentro de la organización judicial chilena", Revista chilena de derecho, 40, 2: pp. 609-634.

Bordalí Salamanca, Andrés (2018): "El régimen de responsabilidad disciplinaria de los jueces chilenos y su inadecuación a las exigencias constitucionales", Ius et Praxis, 24, 2: pp. 513-548.

Brewer-Carías, Allan (1983): "El concepto de Derecho administrativo en Venezuela", Revista de administración pública, 100: pp. 685-704.

Brewer-Carías, Allan (2015): "Sobre el concepto del Derecho Administrativo", en Curso de derecho administrativo iberoamericano (INAP), pp. 25-72.

Bühler, Otto (1955): “Altes und Neues über Begriff und Bedeutung der subjektiven öffentlichen Rechte”, en Jellinek, Walter; Bachof, Otto y Drath Martin (autores), Forschungen und Berichte aus dem öffentlichen Recht. Gedächtnisschrift für (München, Walter Jellinek).

Cea Egaña, José Luis (1979): "Función jurisdiccional y poder judicial”, Revista chilena de derecho, 6, 1: pp. 298-305.

Cea Egaña, José Luis (2008): Derecho Constitucional Chileno (Santiago, Ediciones UC), Tomo IV.

Coing, Helmut (1959 a): Zur Geschichte des Begriffs "subjektives Recht"(Berlin, Metzner).

Coing, Helmut (1959 b): Das subjektive Recht und der Rechtsschutz der Persönlichkeit (Berlin, Metzner).

Colombo Campbell, Juan (1991): La jurisdicción en el Derecho Chileno (Santiago, Editorial Jurídica de Chile).

Colombo Campbell, Juan (2001): "Protección jurisdiccional de la Constitución. La Declaración Judicial de Inconstitucionalidad”, Revista de derecho, 12: pp. 9-30. 
Cordero Quinzacara, Eduardo (2013 a): "Concepto y naturaleza de las sanciones administrativas en la doctrina y jurisprudencia chilena”, Revista de derecho, 20, 1: pp. 79-103.

Cordero Quinzacara, Eduardo (2013 b): “Sanciones administrativas y mercados regulados", Revista de derecho, 26, 1: pp. 119-144.

Damaška, Mirjan (2000): Las caras de la justicia y el poder del estado: análisis comparado del proceso legal (Santiago, Editorial Jurídica de Chile).

Ehlers, Dirk (2010): "Verwaltungs und Verwaltungsrecht im demokratischen und sozialen Rechtsstaat", en Erichsen, Hans-Uwe y Ehlers, Dirk (editores), Allgemeines Verwaltungsrecht (Berlin, Walter de Gruyter), pp. 1-252.

Ferrajoli, luigi et al (2001): Los fundamentos de los derechos fundamentales (Madrid: Trotta).

Ferrajoli, Luigi. (2005): "El papel de la función judicial en el Estado de Derecho. Jurisdicción y argumentación en el Estado constitucional de derecho", en Carbonell, Miguel et al (coordinadores), Jurisdicción y argumentación en el estado constitucional de derecho (México, Universidad Nacional Autónoma de México), pp.

Fezer, K. (1985): "Die Pluralität des Rechts: Prolegomena zu einer pluralistischen Privatrechtstheorie”, JuristenZeitung, 40, 17: pp. 762-771.

Fuenzalida, Pablo y Valderrama, Mario (2017): "La potestad consultiva del Tribunal de Defensa de la Libre Competencia: ¿jurisdiccional o administrativa?", Revista Derecho Administrativo Económico, 13: pp. 181-198.

González Álvarez, Roberto (2014): "El nuevo paradigma de la garantía de la jurisdicción”, Ars Boni et Aequi, 10, 1: pp. 119-150.

Gordillo, Agustín (2017): Tratado de derecho administrativo y obras selectas: Parte general (Buenos Aires, Fundación de Derecho Administrativo).

Gröschner, Rolf. (1997). "Vom Nutzen des Verwaltungsrechtsverhältnisses”, Die Verwaltung, 30: pp. 301 338.

Heintzen, Markus. (1990): “Staatliche Warnungen als Grundrechtsproblem”, VerwArch, 81: pp. 532-556.

Jellinek, Walter (1929): Verwaltungsrecht. Springer-Verlag Berlin Heidelberg GmbH

Krebs, Walter. (1985): “Subjektiver Rechtsschutz und objektive Rechtskontrolle”, en Erichsen, Hans-Uwe, Hoppe, Werner y von Mutius, Albert (editores), System des verwaltungsgerichtlichen Rechtsschutzes Festschrift für Christian-Friedrich Menger zum 70. Geburtstag (Köln, Heymanns).

Lagodny, Otto (1996): Strafrecht vor den Schranken der Grundrechte: die Ermächtigung zum strafrechtlichen Vorwurf im Lichte der Grundrechtsdogmatik dargestellt am Beispiel der Vorfeldkriminalisierung (Tübingen, Mohr Siebeck).

Lübbert Álvarez, Valeria (2011): "El derecho a no ser juzgado por comisiones especiales: análisis crítico de jurisprudencia", Revista de Estudios de la Justicia, 15: pp. 87-105.

Lüke, Gerhard (1959): “Die Abgrenzung der Klagebefugnis im Verwaltungsprozeß”, Archiv des öffentlichen Rechts, 84, 2: pp. 185-226.

Mayer, Otto (1895): Deutsches Verwaltungsrecht (Leipzig, Duncker \& Humblot), Tomo I.

Moraga Klenner, Claudio (2011): “¿xisten en Chile procedimientos administrativos que presentan, también, una naturaleza jurisdiccional?”, Derecho PUCP, 2, 67: pp. 231-251.

Neumeyer, Dieter. (1979): Die Klagebefugnis im Verwaltungsprozess (Berlin, Duncker \& Humblot).

Pacheco Gómez, Máximo (1990): Teoría del Derecho (Santiago, Editorial Jurídica de Chile). 
Penalva, Ernesto (1976): "De la jurisdicción como competencia a la jurisdicción como órgano", Revista de administración pública, 79: pp. 145-161.

Pérez-Cruz Martín, Agustín-Jesús (2015): “Constitución y poder judicial”. Disponible en: https://facultad. pucp.edu.pe/derecho/wp-content/uploads/2015/03/Constituci\%c3\%b3n-y-Poder-Judicial..pdf [Fecha de consulta: 16 de octubre de 2020].

Pietzcker, Jost (1997): "Das Verwaltungsrechtsverhältnis-archimedischer Punkt oder Münchhausens Zopf?", Die Verwaltung, 30, 3: pp. 281-299.

Preu, Peter (1992): Subjektivrechtliche Grundlagen des öffentlichrechtlichen Drittschutzes (Berlin, Duncker $\&$ Humblot).

Ramos Ortells, Manuel (1984): “Aproximación al concepto de potestad jurisdiccional en la Constitución Española”, Anuario de la Facultad de Derecho, 3: pp. 415-458.

Ramsauer, Ulrich (1981): “Die Bestimmung des Schutzbereichs von Grundrechten nach dem Normzweck”, VerwArch, 7289.

Ramsauer, Ulrich (1986): "Die Rolle der Grundrechte im System der subjektiven öffentlichen Rechte”, Archiv des öffentlichen Rechts, 111, 4: pp. 501-536.

Redeker, Konrad (1983): “Entwicklungen und Probleme verwaltungsgerichtlicher Rechtsprechung”, en Festschrift für Hans Ulrich Scupin: Recht und Staat im sozialen Wandel (Berlín, Duncker \& Humblot), pp. 861 y sig.

Rodríguez Collao, Luis (2010): "Bases para distinguir entre infracciones criminales y administrativas", Revista de Derecho de la Pontificia Universidad Católica de Valparaíso, 11: pp. 117-163.

Roth, Andreas (1994): "Verwaltungshandeln mit Drittbetroffenheit und Gesetzesvorbehalt", DOV, 47, 24: pp. 1058 y sig.

Roth, Wolfgang (1994): Faktische Eingriffe in Freiheit und Eigentum: Struktur und Dogmatik des Grundrechtstatbestandes und der Eingriffsrechtfertigung (Berlin, Duncker \& Humblot).

Rupp, Hans (1965): Grundfragen der Heutigen Verwaltungslehre. Tübinger Rechtswissenschaftliche Abhandlungen (Tübingen, Mohr Siebeck).

Schapp, Jan (1977): Das subjektive Recht im Prozeß der Rechtsgewinnung (Berlin, Duncker \& Humblot).

Scherzberg, Arno (1988): "Grundlagen und Typologie des subjektiv-öffentlichen Rechts", Deutsche Verwaltungsblaetter, pp. 129-134.

Schmidt-Aßmann, Eberhard (1991): “Art. 19, IV”. Disponible en: https://beck-online.beck. de/?vpath=bibdata/komm/MaunzDuerigKoGG\%5F69/cont/MaunzDuerigKoGG.htm [Fecha de consulta: 16 de octubre de 2020].

Schmidt-Aßmann, Eberhard (1998): Das allgemeine Verwaltungsrecht als Ordnungsidee. Grundlagen und Aufgaben der verwaltungsrechtlichen Systembildung (Berlin, Springer-Verlag).

Schmidt-Preuß, Matthias (1992): Kollidierende Privatinteressen im Verwaltungsrecht: das subjektive öffentliche Recht im multipolaren Verwaltungsrechtsverhältnis (Berlin, Duncker \& Humblot).

Silva Cimma, Enrique (2009): Derecho administrativo chileno y comparado: introducción y fuentes (Santiago, Editorial Jurídica de Chile), Volumen 1.

Sodan, Helge (2010): " $\$ 42$ Anfechtungs und Verpflichtungsklage; Klagebefugnis". Disponible en: https:// beck-online.beck.de/?vpath=bibdata\%2Fkomm\%2FSodZieKoVwGO_5\%2FVwGO\%2Fcont\%2FSodZieKoVwGO\%2EVwGO\%2Ep42\%2Ehtm [Fecha de consulta: 16 de octubre de 2020].

Soto Kloss, Eduardo (1979): "Derecho Administrativo Penal. Notas para el estudio de la potestad sancionadora de la Administración”, Boletín de investigaciones, 44-45: pp. 95-103. 
Soto Kloss, Eduardo (2013): "Derecho administrativo. Temas fundamentales, tercera edición actualizada, Abeledo Perrot", Revista chilena de derecho, 40, 3: pp. 1021-1022.

Ugarte Cataldo, José Luis (2008): "Inspección del trabajo en Chile: vicisitudes y desafíos", Revista Latinoamericana de Derecho Social, 6: pp. 187-204.

Valdés, Aníbal Bascuñán (1953): Introducción al estudio de las ciencias jurídicas y sociales (Santiago, Editorial Jurídica de Chile).

Wolff, Hans, et al (2007): Verwaltungsrecht (München, CH Beck, 12a edición), Tomo I.

Zúñiga Urbina, Francisco (1998): "Corte Suprema y sus competencias. Notas acerca de su potestad normativa (autos acordados)", Ius et Praxis, 4, 1: pp. 221-234.

Jurisprudencia citada:

BVerwG, 4 de febrero de 1982, 3 C 19.81.

BVerwG, 19 de septiembre de 1986, 4 C 8.84. Disponible en: https://research.wolterskluwer-online.de/ document/93f6977f-3ef8-4050-9501-b2d0195c8d1c. [Fecha de consulta: 16 de octubre de 2020].

BVerwG, 21 de octubre de 1986, 1 C 44.84.

BVerwG, 25 de febrero de 1977, IV C 22.75. Disponible en: https://research.wolterskluwer-online.de/ document/f131cfbe-6274-413a-98d1-b1d5bcca5dd1. [Fecha de consulta: 16 de octubre de 2020].

BVerwG, 15 de julio de 1987, 4 C 56.83. Disponible en: https://research.wolterskluwer-online.de/ document/48ce226d-62d0-4b69-a1f2-e64486167f02. [Fecha de consulta: 16 de octubre de 2020].

BVerwG, 16 de septiembre de 1993, 4 C 28/91. Disponible en: https://research.wolterskluwer-online.de/ document/be057413-4b1a-48cb-993f-1f071cb01a76. [Fecha de consulta: 16 de octubre de 2020].

BVerfGE 8, 197; 14 de octubre de 1958, Bußgeldverfahren. Disponible en: https://www.servat.unibe.ch/ dfr/bv008197.html. [Fecha de consulta: 16 de octubre de 2020].

BVerwGE, 28 de abril de 1967, IV C 10.65. Disponible en: https://dejure.org/ ext/55bee572a3a19ba68c85414ffca61450. [Fecha de consulta: 16 de octubre de 2020].

BVerfGE 22, 49; 6 de junio de 1967, Verwaltungsstrafverfahren. Disponible en: http://www.servat.unibe. ch/dfr/bv022049.html. [Fecha de consulta: 16 de octubre de 2020].

BVerfGE 27, 18; 16 de julio de 1969, Ordnungswidrigkeiten. Disponible en: http://www.servat.unibe. ch/dfr/bv027018.html. [Fecha de consulta: 16 de octubre de 2020].

Corte Constitucional de Colombia, 22 de noviembre de 2006, Sentencia C-961/06. Disponible en: https://www.corteconstitucional.gov.co/relatoria/2006/C-961-06.htm. [Fecha de consulta: 16 de octubre de 2020].

Corte Constitucional de Colombia, 9 de mayo de 2012, Sentencia C-330/12. Disponible en: https:// www.corteconstitucional.gov.co/relatoria/2012/C-330-12.htm. [Fecha de consulta: 16 de octubre de 2020].

Corte Suprema, 16 de septiembre de 2013, Rol No 7.397-2012. Disponible en: http://basejurisprudencial. poderjudicial.cl. [Fecha de consulta: 16 de octubre de 2020].

Tribunal Constitucional, 23 de enero de 1991, Rol No 119-91. Disponible en: https://www. tribunalconstitucional.cl/ver2.php?id=493. [Fecha de consulta: 16 de octubre de 2020].

Tribunal Constitucional, 19 de enero de 1993, Rol 165-93. Disponible en: https://www. tribunalconstitucional.cl/ver2.php?id=449. [Fecha de consulta: 16 de octubre de 2020].

Tribunal Constitucional, 22 de noviembre de 1993, Rol No 176. Disponible en: https://www. tribunalconstitucional.cl/ver2.php?id=440. [Fecha de consulta: 16 de octubre de 2020]. 
Tribunal Constitucional, 14 de septiembre de 1994, Rol No 195-94. Disponible en: https://www. tribunalconstitucional.cl/ver2.php?id=421. [Fecha de consulta: 16 de octubre de 2020].

Tribunal Constitucional, 11 de junio de 1996, Rol No 236-96. Disponible en: https://www. tribunalconstitucional.cl/ver2.php?id=381. [Fecha de consulta: 16 de octubre de 2020].

Tribunal Constitucional, 8 deabrilde2002, Rol No 346. Disponible en: https://www.tribunalconstitucional. $\mathrm{cl} / \mathrm{ver} 2$.php?id=274. [Fecha de consulta: 16 de octubre de 2020].

Tribunal Constitucional, 17 de septiembre de 2002, Rol No 360-02. Disponible en: https://www. tribunalconstitucional.cl/ver2.php?id=260. [Fecha de consulta: 16 de octubre de 2020].

Tribunal Constitucional, 20 de marzo de 2006, Rol No 606-2006. Disponible en: https://www. tribunalconstitucional.cl/ver2.php?id=97. [Fecha de consulta: 16 de octubre de 2020].

Tribunal Constitucional, 27 de junio de 2006, Rol No 480-06. Disponible en: https://www. tribunalconstitucional.cl/ver2.php?id=616. [Fecha de consulta: 16 de octubre de 2020].

Tribunal Constitucional, 8 de agosto de 2006, Rol No 478-06. Disponible en: https://www. tribunalconstitucional.cl/ver2.php?id=151. [Fecha de consulta: 16 de octubre de 2020].

Tribunal Constitucional, 2 de enero de 2007, Rol No 513-06. Disponible en: https://www. tribunalconstitucional.cl/ver2.php?id=142. [Fecha de consulta: 16 de octubre de 2020].

Tribunal Constitucional, 26 de junio de 2008, Rol No 725-2007. Disponible en: https://www. tribunalconstitucional.cl/ver2.php?id=962. [Fecha de consulta: 16 de octubre de 2020].

Tribunal Constitucional, 8 de enero de 2009, Rol No 1183-08. Disponible en: https://www. tribunalconstitucional.cl/ver2.php?id=1077. [Fecha de consulta: 16 de octubre de 2020].

Tribunal Constitucional, 21 de octubre de 2009, Rol No 1518-09. Disponible en: https://www. tribunalconstitucional.cl/ver2.php?id=1587. [Fecha de consulta: 16 de octubre de 2020].

Tribunal Constitucional, 26 de noviembre de 2009, Rol No 1536-09. Disponible en: https://www. tribunalconstitucional.cl/ver2.php?id=1263. [Fecha de consulta: 16 de octubre de 2020].

Tribunal Constitucional, 7 de septiembre de 2010, Rol No 1448-09. Disponible en: https://www. tribunalconstitucional.cl/ver2.php?id=1522. [Fecha de consulta: 16 de octubre de 2020].

Tribunal Constitucional, 28 de octubre de 2010, Rol No 1393-09. Disponible en: https://www. tribunalconstitucional.cl/ver2.php?id=1601. [Fecha de consulta: 16 de octubre de 2020].

Tribunal Constitucional, 21 de junio de 2011, Rol No 1732-10. Disponible en: https://www. tribunalconstitucional.cl/ver2.php?id=1983. [Fecha de consulta: 16 de octubre de 2020].

Tribunal Constitucional, 16 de mayo de 2012, Rol No 2191-12. Disponible en: https://www. tribunalconstitucional.cl/ver2.php?id=2395. [Fecha de consulta: 16 de octubre de 2020].

Tribunal Constitucional, 10 de julio de 2012, Rol No 2042-11. Disponible en: https://www. tribunalconstitucional.cl/ver2.php?id=2465. [Fecha de consulta: 16 de octubre de 2020].

Tribunal Constitucional, 20 de agosto de 2013, Rol No 2381-12. Disponible en: https://www. tribunalconstitucional.cl/ver2.php?id=2822. [Fecha de consulta: 16 de octubre de 2020].

Tribunal Constitucional, 6 de Agosto de 2015, Rol 2690. Disponible en https://www.tribunalconstitucional. cl/ver2.php?id=3145. [Fecha de consulta: 16 de octubre de 2020].

Tribunal Constitucional, 30 de Diciembre de 2015, Rol No 2865. Disponible en: https://www. tribunalconstitucional.cl/ver2.php?id=3217. [Fecha de consulta: 16 de octubre de 2020].

Tribunal Constitucional, 12 de julio de 2016, Rol No 3106-16-CPR. Disponible en: https://www. tribunalconstitucional.cl/ver2.php?id=3292. [Fecha de consulta: 16 de octubre de 2020]. 
El concepto de la función administrativa y su delimitación frente a los actos de naturaleza jurisdiccional

Tribunal Constitucional, 13 de octubre de 2016, Rol 2921-15. Disponible en: https://www. tribunalconstitucional.cl/ver2.php?id=3341. [Fecha de consulta: 16 de octubre de 2020].

Tribunal Constitucional, 15 de noviembre de 2016, Rol No 3028-16. Disponible en: https://www. tribunalconstitucional.cl/ver2.php?id=3351. [Fecha de consulta: 16 de octubre de 2020].

Tribunal Constitucional, 18 de enero de 2018, Rol No 4012-17-CPR. Disponible en: http://www. tribunalconstitucional.cl/wp/ver.php?id=3621. [Fecha de consulta: 16 de octubre de 2020].

Tribunal Constitucional, 31 de Mayo de 2018, Rol No 3594-17. Disponible en: http://jurisprudencia. vlex.cl/vid/727329889. [Fecha de consulta: 16 de octubre de 2020].

Tribunal Constitucional, 12 de julio de 2018, Rol No 4945-18. Disponible en: https://www. tribunalconstitucional.cl/ver2.php?id=3902. [Fecha de consulta: 16 de octubre de 2020].

Tribunal Constitucional, 19 de julio de 2018, Rol 4847-18. Disponible en: https://www. tribunalconstitucional.cl/ver2.php?id=3905. [Fecha de consulta: 16 de octubre de 2020].

\section{Bibliografía sugerida:}

Barona Vilar, Silvia (2011): "Las ADR en la justicia del siglo XXI, en especial la mediación”, Revista de derecho, 18, 1: pp. 185-211.

Bensusán, Graciela (2009): "La Inspección del Trabajo en América Latina: teorías, contextos y evidencias", Estudios sociológicos, pp. 989-1040.

Blanco Vergara, Alejandro (2004): "Esquema de los principios del derecho administrativo sancionador", Revista de derecho, 11, 2: pp. 137-147.

Boettiger Philipps, Camila (2009): "El derecho administrativo sancionador en la jurisprudencia del Tribunal Constitucional”. Revista Actualidad Jurídica, 20, 577. Disponible en: https://derecho.udd. cl/centro-justicia-constitucional/files/2015/12/El_derecho_administrativo_sancionador_en.pdf. [Fecha de consulta: 23 de octubre de 2019].

Bordalí Salamanca, Andrés (2004): “Justicia privada”, Revista de derecho, 16: pp. 165-186.

Brühl, Raimund (2006): Verwaltungsrecht für die Fallbearbeitung. Praktische Anleitungen zum Erwerb prüfungsrelevanter Kenntnisse und Fertigkeiten (Stuttgart, W. Kohlhammer Verlag).

Bull, Hans y Mehde, Veith (2014): Allgemeines Verwaltungsrecht mit Verwaltungslehre (Heidelberg, CF Müller).

Cabrera Delgado, José Manuel (2014): "Duplicidad sancionadora en el ámbito administrativo y penal”, Avances en Supervisión Educativa, 22.

Chocrón Giráldez, Ana María. (2005): "La exclusividad y la unidad jurisdiccionales como principios constitucionales en el ordenamiento jurídico español", Boletín mexicano de derecho comparado, 38, 113: pp. 651-687.

Cordero Quinzacara, Eduardo (2014): "Los principios que rigen la potestad sancionadora de la Administración en el derecho chileno", Revista de derecho, 42: pp. 399-439.

Cordero Quinzacara, Eduardo y Aldunate Lizana, Eduardo (2012): "Las bases constitucionales de la potestad sancionadora de la Administración”, Revista de derecho, 39: pp. 337-361.

Couso, Jaime (2018): "Autoría y participación en el derecho sancionatorio administrativo. Hacia una topografía del problema”, Ius et Praxis, 24, 1: pp. 437-496. 
Gómez Barboza, P. (2010): "La mediación, una forma alternativa de resolución de conflictos. su naturaleza, esencia, características, estructura, ventajas y desventajas frente a la solución judicial”, Revista de Derecho de la Pontificia Universidad Católica de Valparaíso, 20: pp. 377-398.

Jequier Lehuedé, Eduardo (2018): "La ejecución del acuerdo de mediación en asuntos civiles y comerciales. Una revisión impostergable", Revista de derecho, 31, 2: pp. 71-93.

Letelier Wartenberg, Raúl (2017): “Garantías penales y sanciones administrativas”, Política criminal, 12, 24: pp. 622-689.

Nieva Fenoll, Jordi (2017): "Seis conceptos en busca de un objetivo: jurisdicción, acción, proceso, derechos, pena y delito", Politica criminal, 12, 23: pp. 103-123.

Pérez Ragone, Álvaro y Copani, Juan (2010): “Los llamados medios alternativos de resolución de conflictos vistos desde el proceso civil. ¿La justa realización del derecho material vs la resolución de conflictos?”, Revista de Derecho de la Pontificia Universidad Católica de Valparaíso, 2, 1: pp. 155-183.

Román Cordero, Cristian (2010): "El castigo en el Derecho Administrativo", Derecho y Humanidades, 1, 16: pp. 155-171.

Van Weezel, Alex (2017): "Sobre la necesidad de un cambio de paradigma en el derecho sancionatorio administrativo", Politica criminal, 12, 24: pp. 997-1043.

Von Münch, Ingo (2016): "Verwaltung und Verwaltungsrecht im demokratischen und sozialen Rechtsstaat" en Erichsen, Hans-Uwe y Martens, Wolfgang (coordinadores), Allgemeines Verwaltungsrecht (Berlin, De Gruyter).

Wienbracke, Mike (2012): Allgemeines Verwaltungsrecht (Heidelberg, CF Müller).

Zúñiga Urbina, Francisco (2007): "Autonomías constitucionales e instituciones contramayoritarias (a propósito de las aporías de la 'democracia constitucional')", Ius et Praxis, 13, 2: pp. 223-244.

Jurisprudencia sugerida:

BVerwG, 3 de noviembre de 2011, 7 C 3.11. Disponible en: https://www.bverwg.de/031111U7C3.11.0. [Fecha de consulta: 16 de octubre de 2020].

Tribunal Constitucional, 26 de agosto de 1996, Rol 244-96. Disponible en: https://www. tribunalconstitucional.cl/ver2.php?id=926. [Fecha de consulta: 16 de octubre de 2020].

Tribunal Constitucional, 6 de septiembre de 2007, Rol No 616-06. Disponible en: https://www. tribunalconstitucional.cl/ver2.php?id=93. [Fecha de consulta: 16 de octubre de 2020].

Tribunal Constitucional, 3 de enero de 2008, Rol No 792-07. Disponible en: https://www. tribunalconstitucional.cl/ver2.php?id=728. [Fecha de consulta: 16 de octubre de 2020].

Tribunal Constitucional, 18 de abril de 2008, Rol No 740. Disponible en: http://jurisprudencia.vlex.cl/ vid/-58941744. [Fecha de consulta: 16 de octubre de 2020].

Tribunal Constitucional, 26 de junio de 2008, Rol No 766-2007. Disponible en: http://www. tribunalconstitucional.cl/ver.php?id=963. [Fecha de consulta: 16 de octubre de 2020].

Tribunal Constitucional, 3 de junio de 2010, Rol No 567-06. Disponible en: https://www. tribunalconstitucional.cl/ver2.php?id=1386. [Fecha de consulta: 16 de octubre de 2020].

Tribunal Constitucional, 7 de diciembre de 2010, Rol 1564-09. Disponible en: https://www. tribunalconstitucional.cl/ver2.php?id=1665. [Fecha de consulta: 16 de octubre de 2020].

Tribunal Constitucional, 26 de noviembre de 2013, Rol No 2402-13. Disponible en: https://www. tribunalconstitucional.cl/ver2.php?id=2865. [Fecha de consulta: 16 de octubre de 2020].

Tribunal Constitucional, 4 de julio de 2017, Rol No 2897-15. Disponible en: https://www. tribunalconstitucional.cl/ver2.php?id=3447. [Fecha de consulta: 16 de octubre de 2020]. 